Article

\title{
Pediatric Patients Receiving Specialized Palliative Home Care According to German Law: A Prospective Multicenter Cohort Study
}

\author{
Silke Nolte-Buchholtz ${ }^{1, *}$, Boris Zernikow ${ }^{2,3}$ and Julia Wager ${ }^{2,3}$ \\ 1 Department of Pediatrics, University Hospital Carl Gustav Carus, Technische Universität Dresden, \\ Fetscherstrasse 74, 01307 Dresden, Germany \\ 2 Department of Children's Pain Therapy and Pediatric Palliative Care, Faculty of Health, School of Medicine, \\ Witten/Herdecke University, 58455 Witten, Germany; boris.zernikow@kinderklinik-datteln.de or \\ b.zernikow@kinderklinik-datteln.de (B.Z.); j.wager@deutsches-kinderschmerzzentrum.de (J.W.) \\ 3 Paediatric Palliative Care Centre, Children's and Adolescents' Hospital, 45711 Datteln, Germany \\ * Correspondence: silke.nolte-buchholtz@ukdd.de; Tel.: +49-351-458-5226; Fax: +49-351-458-6384
}

Received: 2 May 2018; Accepted: 28 May 2018; Published: 31 May 2018

\begin{abstract}
In Germany, every child with a life-limiting condition suffering from symptoms that cannot sufficiently be controlled is eligible by law for specialized pediatric palliative home care (SPPHC). It is the aim of this study to describe the demographic and clinical characteristics of children referred to SPPHC and to compare patients with cancer and non-cancer conditions. The prospective multicenter study includes data on 75 children (median age 7.7 years, 50.7\% male). The majority had non-cancer conditions (72\%). The most common symptoms were cognitive impairment, somatic pain, impairment in communication or swallowing difficulties. Swallowing difficulties, seizures, and spasticity occurred significantly more often in non-cancer patients $(p<0.01)$. Cancer patients received antiemetics significantly more often (permanent and on demand) than non-cancer patients $(p<0.01)$. Significantly more non-cancer patients had some type of feeding tube $(57.3 \%)$ or received oxygen $(33.3 \%)(p<0.01)$. Central venous catheters had been fitted in $20 \%$ of the patients, mostly in cancer patients $(p<0.001)$. Tracheostomy tubes $(9.3 \%)$ or ventilation $(14.7 \%)$ were only used in non-cancer patients. In conclusion, patients referred to SPPHC are a diverse cohort with complex conditions including a large range of neurologically originating symptoms. The care of pediatric palliative care patients with cancer is different to the care of non-cancer patients.
\end{abstract}

Keywords: palliative care; pediatrics; cancer; non-cancer; home care

\section{Introduction}

In recent years, profound developments and improvements in the field of palliative care have taken place in Germany. Since 2007, a new law has guaranteed access to specialized (tertiary) palliative home care (SPHC) for children and adults with a life-limiting disease suffering from symptoms that cannot sufficiently be controlled in primary or secondary care. Only if these conditions are fulfilled and approved by the insurance company the patient has the right to receive SPHC. According to the law, the main tasks of SPHC are counseling, coordination and provision of palliative nursing and medical care, including a $24 / 7$ on-call service. The law also provides quality criteria for the composition of SPHC, e.g., a certified qualification of team members and a close collaboration between specialized palliative care nurses and physicians. The $24 / 7$ on-call duty also determines a minimum number of team members. Specialized palliative home care is delivered in close cooperation with local health care professionals, such as general practitioners, pediatricians in private practice, nursing and hospice services, and local hospitals. The costs for SPHC, whether taking place in the patient's 
familiar domestic surrounding, inpatient nursing facilities, or hospices until death, are covered by health insurance when prescribed by a physician and when the patient fulfills the strict criteria defined by law [1].

Little is known about the demographic or clinical characteristics of children who are referred to specialized pediatric palliative home care (SPPHC) services or about the reasons for referrals to those services.

In adult SPHC patients, the mean age is more than 65 years. A majority of these patients suffer from cancer (75-94\%), and the main symptoms are tiredness, fatigue, pain, and loss of appetite [2-4].

So far, only one study in Germany has investigated the characteristics of children receiving SPHC in comparison with characteristics of adults [5]. This study was conducted in a single center for palliative medicine, with one SPHC team for adults and one for children. Compared with the adult palliative patients, the pediatric group showed a greater diversity of diseases, with a relatively small patient group suffering from cancer. The pediatric group showed distinctive patterns of symptoms and the use of specific medications other than adults.

The aim of this prospective multicenter cohort study was to study the characteristics of patients who are referred to nine SPPHC teams in Germany. First, demographic and medical data of the pediatric patients were described. Second, care goals were analyzed. Furthermore, the study aimed to identify differences between pediatric non-cancer and cancer patients regarding symptoms, treatment measures, and goals of consultation.

\section{Materials and Methods}

The multicenter study was carried out between April 2013 and September 2013 in nine of fourteen SPPHC teams in Germany.

\subsection{Recruitment and Data Collection}

A questionnaire was sent to the participating SPPHC teams. At each site, data on new referrals were obtained from patients' medical charts over a time-period of three months. Before study participation, families received written study information. Patients were only included in the study if informed consent was provided by the parents. Additionally, patients able to communicate were informed about the study and asked for their assent.

Once the questionnaires were completed by the SPPHC team, they were sent back to the coordinating principal investigator at the University Hospital for children and adolescents in Dresden, Germany. The principal investigator compiled a master database and entered all data from the questionnaires into the database.

Information on the following categories was retrieved by the SPPHC teams for the time of referral:

1. Demographic data: patient age, gender, migration background, patient residence, siblings with life-limiting conditions.

2. Clinical information: current symptoms, medication, medical devices, non-pharmacological treatment.

3. Characteristics of the referral: principal underlying diagnosis, care goals.

Age was defined at the time of cohort entry based on date of birth and was categorized into the following groups: 0-1 month, 2-11 months, 1-9 years, 10-18 years, and older than 18 years of age. Migration background was defined as follows: the child immigrated into Germany and at least one parent was born in a country other than Germany, both parents immigrated into Germany, or neither parent had German citizenship [6].

The principal underlying diagnoses were categorized by the principal investigator, who is a pediatrician in the subspecialty palliative care. Categories for diagnoses were divided first into cancer and non-cancer and second into solid tumor, brain tumor, leukemia, neuromuscular (e.g., cerebral palsy), neurodegenerative, cardiovascular, respiratory, gastrointestinal, chromosomal aberration, and other conditions. The care goals were described by the SPPHC teams. The symptom prevalence and 
burden was assessed by the consulted SPPHC team. Permanent medication therapy or on-demand medication was retrieved from the medical chart.

\subsection{Statistics}

Descriptive statistics were used to characterize the study cohort. Comparisons of the two groups of cancer and non-cancer patients were computed using the $t$-test, the chi-square test, or Fisher's exact test, depending on the variable analyzed. A two-tailed $p$-value of $<0.05$ was considered significant. For all analyses, Bonferroni adjustments were conducted. Statistical analyses were performed using IBM SPSS, version 22 (IBM, Chicago, IL, USA).

\subsection{Ethics}

The ethics committee of the University of Dresden, Germany approved the study. The approval code is EK 384122012; date of approval is 4 December 2012.

\section{Results}

Between April and September 2013, the nine SPPHC teams included $N=75$ new patients into SPPHC.

\subsection{Sample Characteristics}

A total of 54 children (72\%) suffered from non-oncologic conditions. The most common diagnoses were neuromuscular diseases ( $37 \%)$, followed by solid tumors (15\%; see Table 1$)$.

Table 1. Diagnoses of patients in the cohort.

\begin{tabular}{ccc}
\hline Diagnoses $(\boldsymbol{N}=\mathbf{7 5})$ & $\boldsymbol{n}$ & $\mathbf{\%}$ \\
\hline Cancer & 21 & 28.1 \\
Solid tumor & 11 & 14.7 \\
Brain tumor & 8 & 10.7 \\
Leukemia & 2 & 2.7 \\
\hline Non-Cancer & 54 & 71.9 \\
Neuromuscular & 28 & 37.0 \\
Neurodegenerative & 9 & 12.0 \\
Chromosomal Aberration & 6 & 8.0 \\
Cardiovascular & 6 & 8.0 \\
Respiratory & 1 & 1.3 \\
Gastrointestinal & 1 & 1.3 \\
Other $^{\text {a }}$ & 3 & 4.0 \\
\hline
\end{tabular}

a VACTERL association (vertebral defects, anal atresia, cardiac defects, tracheo-esophageal fistula, renal anomalies, and limb abnormalities), agenesis of the pons, Lennox encephalopathy.

Characteristics of the study sample are summarized in Table 2. Gender was equally distributed within the sample. The median age of children was 7.7 years, ranging from 0 to 31 years (interquartile range $=13.1$ years). A total of $10(13.3 \%)$ patients were older than 18 years of age. Most patients lived with both parents (71\%). Sixteen percent of patients (12 of 57) displayed a migration background. No significant differences could be found between the cancer and the non-cancer groups regarding gender, age, residence characteristics, and migration background. 
Table 2. Patient characteristics.

\begin{tabular}{|c|c|c|c|c|c|c|c|c|c|}
\hline \multirow[t]{2}{*}{ Characteristics } & \multicolumn{2}{|c|}{ Total Patients } & \multicolumn{2}{|c|}{ Cancer Patients } & \multicolumn{2}{|c|}{ Non-Cancer Patients } & \multicolumn{3}{|c|}{ Statistics } \\
\hline & $n$ & $\%$ & $n$ & $\%$ & $n$ & $\%$ & $d f$ & Chi-Square & $p$-Value \\
\hline Gender $(n=69)$ & & & & & & & 1 & 0.006 & 1.000 \\
\hline Female & 34 & 49.3 & 10 & 50.0 & 24 & 49.0 & & & \\
\hline Male & 35 & 50.7 & 10 & 50.0 & 25 & 51.0 & & & \\
\hline Age $(N=75)$ & & & & & & & 4 & 7.45 & 0.114 \\
\hline $0-1$ month & 1 & 1.3 & 0 & 0.0 & 1 & 1.9 & & & \\
\hline 2-11 month & 15 & 20.0 & 1 & 4.8 & 14 & 25.9 & & & \\
\hline 1-9 years & 27 & 36.0 & 8 & 38.1 & 19 & 35.2 & & & \\
\hline 10-18 years & 22 & 29.3 & 10 & 47.6 & 12 & 22.2 & & & \\
\hline Older than 18 years & 10 & 13.3 & 2 & 9.5 & 8 & 14.8 & & & \\
\hline Migration background & & & & & & & 2 & 0.42 & 0.810 \\
\hline With migration background ${ }^{1}$ & 12 & 16.0 & 3 & 20.0 & 9 & 21.4 & & & \\
\hline Residence $(N=75)$ & & & & & & & 2 & 3.99 & 0.136 \\
\hline With both parents & 53 & 70.7 & 17 & 81.0 & 36 & 66.6 & & & \\
\hline Only/mostly with mother & 13 & 17.3 & 4 & 19.0 & 9 & 16.7 & & & \\
\hline Other $^{2}$ & 9 & 12 & 0 & 0.0 & 9 & 16.7 & & & \\
\hline Siblings with LLC $(n=72)$ & & & & & & & 2 & 3.01 & 0.222 \\
\hline Siblings with LLC & 7 & 9.7 & 0 & 0.00 & 7 & 100.0 & & & \\
\hline
\end{tabular}

${ }^{1}$ Definition [6]; ${ }^{2}$ Includes grandmother, hospice for adults, hospice for children $(n=2)$, sheltered accommodation, five of nine patients are older than 18 years; LLC, life-limiting conditions; $d f$, degrees of freedom.

\subsection{Palliative Care Consultative Encounter Characteristics/Treatment Goals}

In all cases, there was more than one care goal. For the majority of patients, counseling (93.2\%) and symptom management $(89.2 \%)$ were considered care goals. Additional care goals were empowerment $(71.6 \%)$, communication about symptoms or about the disease course $(68.9 \%)$, and decision-making support $(64.9 \%)$. There were no significant differences between the cancer and the non-cancer group (see Table 3).

Table 3. Care goals.

\begin{tabular}{|c|c|c|c|c|c|c|c|}
\hline \multirow[t]{2}{*}{ Characteristics } & \multicolumn{2}{|c|}{$\begin{array}{l}\text { Total Patients } \\
\quad(n=74)\end{array}$} & \multicolumn{2}{|c|}{$\begin{array}{l}\text { Cancer Patients } \\
\quad(n=21)\end{array}$} & \multicolumn{2}{|c|}{$\begin{array}{c}\text { Non-Cancer } \\
\text { Patients }(n=53)\end{array}$} & \multirow[b]{2}{*}{$p$-Value ${ }^{\mathrm{c}}$} \\
\hline & $n$ & $\%$ & $n$ & $\%$ & $n$ & $\%$ & \\
\hline Counsel $^{a}$ & 69 & 93.2 & 19 & 90.5 & 50 & 94.3 & 0.618 \\
\hline Symptom management & 66 & 89.2 & 20 & 95.2 & 46 & 86.8 & 0.427 \\
\hline Empowerment ${ }^{b}$ & 53 & 71.6 & 13 & 61.9 & 40 & 75.5 & 0.264 \\
\hline $\begin{array}{l}\text { Communication about } \\
\text { symptoms/course of disease }\end{array}$ & 51 & 68.9 & 16 & 76.2 & 35 & 66 & 0.578 \\
\hline Decision-making support & 48 & 64.9 & 16 & 76.2 & 32 & 60.4 & 0.282 \\
\hline Transition to home & 15 & 20.3 & 6 & 28.6 & 9 & 17.0 & 0.388 \\
\hline Logistic and coordination of care & 34 & 45.9 & 10 & 47.6 & 24 & 45.3 & 1.000 \\
\hline Discuss DNAR order & 34 & 45.9 & 11 & 52.4 & 23 & 43.4 & 0.606 \\
\hline Consultation of further provider/carer & 25 & 33.8 & 8 & 38.1 & 17 & 32.1 & 0.786 \\
\hline
\end{tabular}

${ }^{a}$ Counseling of the patient $(n=24)$, the family $(n=62)$, the pediatrician $(n=34)$, the nursing service $(n=23)$, the health care service provider $(n=6)$. Counseling of the patient and the nursing service is significant between cancer and non-cancer group $(<0.001) ;{ }^{b}$ Empowerment of the patient $(n=13)$, the family $(n=49)$, the pediatrician $(n=7)$, the nursing service $(n=17)$. Empowerment of the patient is significant between cancer and non-cancer group $(p<0.001) ;{ }^{c}$ Fisher-test; DNAR, do not attempt resuscitation.

\subsection{Symptoms}

The most common symptoms when patients were admitted into SPPHC were impairment in communication, somatic pain, swallowing difficulties and cognitive impairment.

Patients suffering from pain $(61 \% ; n=46)$ could be grouped into the following categories: suffering from somatic pain (85\%), suffering from neuropathic pain (35\%) and suffering from visceral pain (24\%). The frequencies of all symptoms are shown in Figure 1. 


\section{Symptoms}

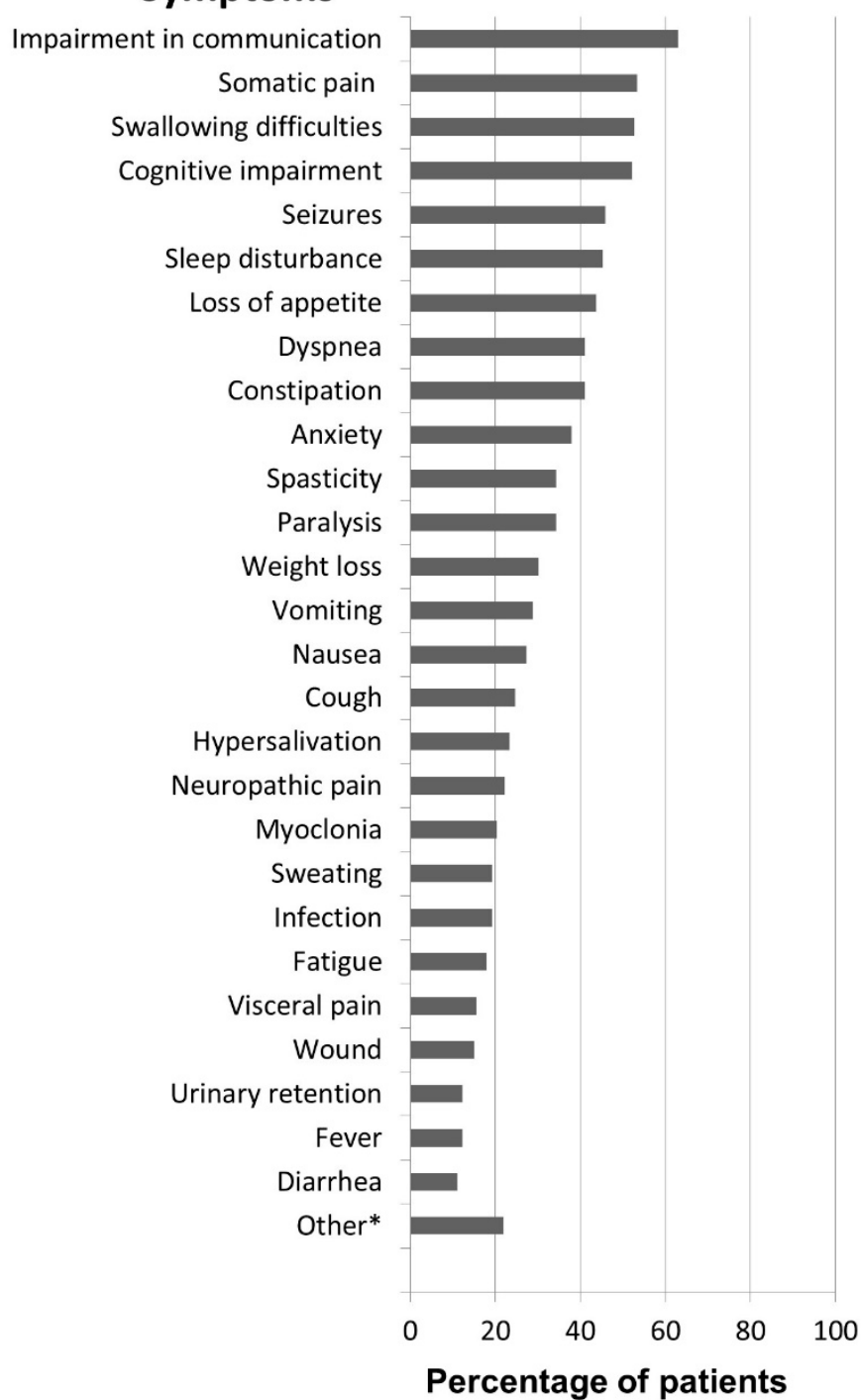

Figure 1. Symptom prevalence. * Other: hypothermia, dry mouth, edema, itching.

The prevalence of specific symptoms differed between cancer and non-cancer patients. Swallowing difficulties, seizures and spasticity occurred significantly more in the non-cancer population (see Table 4).

The SPPHC teams also rated whether a symptom would be considered burdensome and needed treatment. Dyspnea was regarded as burdensome in all cases, and somatic pain was burdensome in all but one of the cases. In the cancer group, swallowing difficulties were considered a burdensome symptom in all cases, whereas this was only true for $15 \%$ of patients in the non-cancer group. Impairment in communication was classified as burdensome in $44 \%$ of patients (four of nine) in the cancer group and in 19\% of patients (6 of 32) in the non-cancer group (see Figure 2). 
Table 4. Symptoms in cancer and non-cancer patients.

\begin{tabular}{|c|c|c|c|c|}
\hline & $\begin{array}{c}\text { Total Patients } \\
n(\%)\end{array}$ & $\begin{array}{c}\text { Cancer } \\
\text { Patients } n(\%)\end{array}$ & $\begin{array}{l}\text { Non-Cancer } \\
\text { Patients } n(\%)\end{array}$ & $p$-Value ${ }^{\text {a }}$ \\
\hline Impairment in communication & $46(63.0)$ & $9(42.9)$ & $37(71.2)$ & 0.033 \\
\hline Swallowing difficulties & $39(52.7)$ & $5(23.8)$ & $34(66.0)$ & $0.002 *$ \\
\hline Somatic pain & $39(53.4)$ & $13(61.9)$ & $26(50.0)$ & 0.441 \\
\hline Cognitive impairment & $38(52.1)$ & $6(28.6)$ & $32(61.5)$ & 0.019 \\
\hline Seizures & $33(45.8)$ & $2(9.5)$ & $31(60.8)$ & $<0.001 *$ \\
\hline Sleep disturbance & $33(45.2)$ & $12(57.1)$ & $21(40.4)$ & 0.207 \\
\hline Loss of appetite & $32(43.8)$ & $12(57.1)$ & $20(38.5)$ & 0.194 \\
\hline Constipation & $30(41.1)$ & $7(33.3)$ & $23(44.2)$ & 0.441 \\
\hline Dyspnea & $30(41.1)$ & $4(19.0)$ & $26(50.0)$ & 0.019 \\
\hline Anxiety & $27(38.0)$ & $13(65.0)$ & $14(27.5)$ & 0.006 \\
\hline Paralysis & $25(34.2)$ & $7(33.3)$ & $18(34.6)$ & 1.000 \\
\hline Spasticity & $25(34.2)$ & $0(0.0)$ & $25(48.1)$ & $<0.001 *$ \\
\hline Weight loss & $22(30.1)$ & $8(38.1)$ & $14(26.9)$ & 0.403 \\
\hline Vomiting & $21(28.8)$ & $8(38.1)$ & $13(25.0)$ & 0.271 \\
\hline Nausea & $20(27.4)$ & $8(38.1)$ & $12(23.1)$ & 0.248 \\
\hline Cough & $18(24.7)$ & $3(14.3)$ & $15(28.8)$ & 0.241 \\
\hline Hypersalivation & $17(23.3)$ & $1(4.8)$ & $16(30.8)$ & 0.017 \\
\hline Neuropathic pain & $16(22.2)$ & $3(14.3)$ & $13(25.5)$ & 0.365 \\
\hline Myoclonia & $15(20.3)$ & $1(4.8)$ & $14(26.4)$ & 0.053 \\
\hline Infection & $14(19.2)$ & $4(19.0)$ & $10(19.2)$ & 1.000 \\
\hline Sweating & $14(19.2)$ & $1(4.8)$ & $13(25.0)$ & 0.092 \\
\hline Fatigue & $13(17.8)$ & $8(38.1)$ & $5(9.6)$ & 0.007 \\
\hline Visceral pain & $11(15.5)$ & $4(19.0)$ & $7(14.0)$ & 0.721 \\
\hline Wound & $11(15.1)$ & $4(19.0)$ & 7 (13.5) & 0.719 \\
\hline Urinary retention & $9(12.3)$ & $4(19.0)$ & $5(9.6)$ & 0.269 \\
\hline Fever & $9(12.2)$ & $5(23.8)$ & $4(7.5)$ & 0.107 \\
\hline Diarrhea & $8(11.0)$ & $4(19.0)$ & $4(7.7)$ & 0.216 \\
\hline Other ${ }^{b}$ & 16 & 5 & 11 & \\
\hline
\end{tabular}

a Fisher's exact test; b Other: hypothermia, dry mouth, edema, itching; ${ }^{*}$ result is significant after Bonferroni-Holm correction.

\subsection{Medication and Other Therapy}

At the time of admission into SPPHC, approximately $57 \%$ of the patients had some type of feeding tube, of whom all but one were non-cancer patients $(p<0.001)$. Central venous catheters had been fitted in $20 \%$ of the patients, eleven of whom were cancer patients $(p<0.001)$. A tracheostomy tube had been attached to $9.3 \%$ of the patients, and a total of nearly $15 \%$ received invasive or non-invasive ventilation ( $8 \%$ and $6.7 \%$, respectively). One child with severe cerebral palsy had an intrathecal Baclofen pump. All patients with tracheostomy or ventilation had a non-cancer condition.

One third of the patients received oxygen, all of whom (except one) were non-cancer patients $(p=0.003)$. Children with non-cancer diagnoses received significantly more non-medication therapy than did those with cancer diagnoses (see Table 5). 


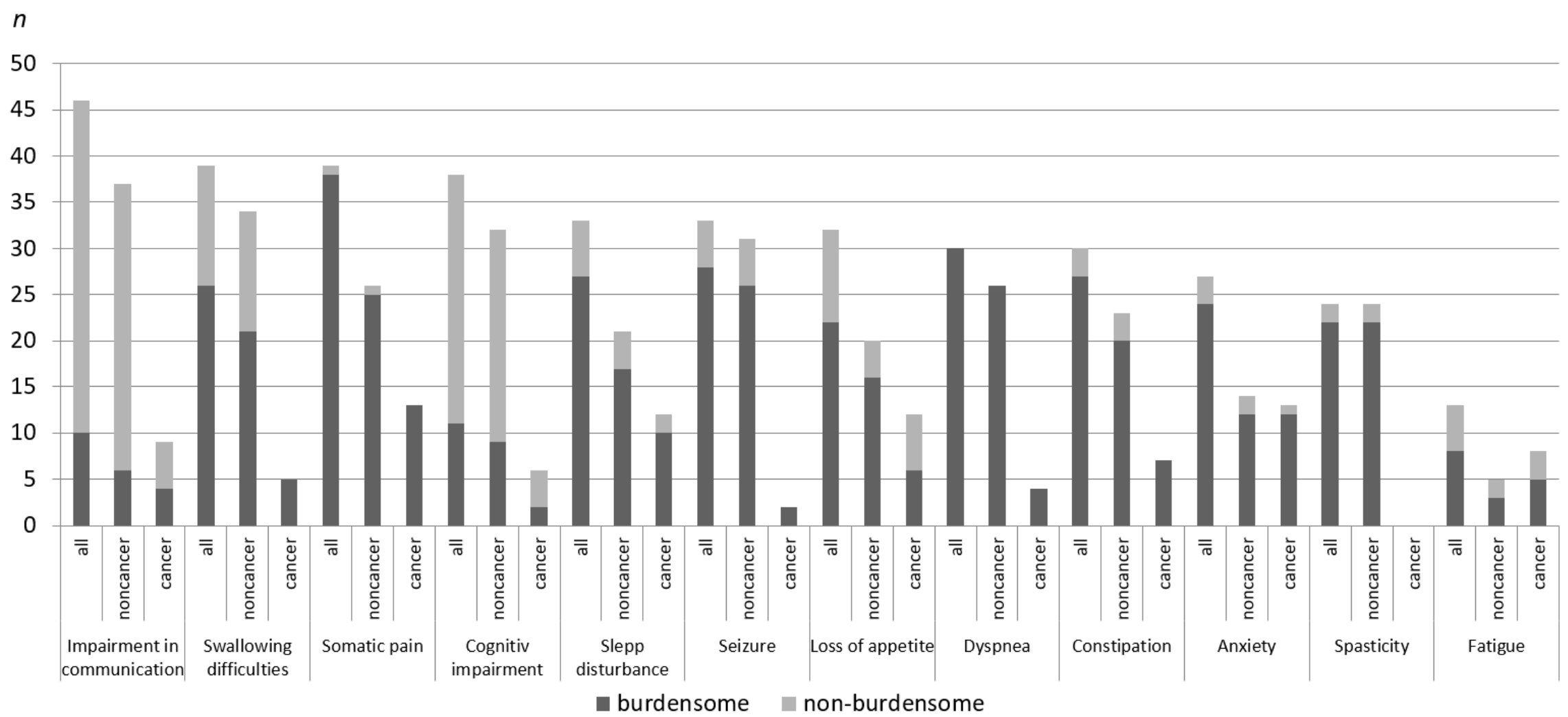

Figure 2. Symptom burden in patients with cancer and non-cancer condition. 
Table 5. Clinical characteristics of cancer and non-cancer patients.

\begin{tabular}{|c|c|c|c|c|c|c|c|}
\hline \multirow[t]{2}{*}{ Characteristics } & \multicolumn{2}{|c|}{ All Patients } & \multicolumn{2}{|c|}{ Cancer Patients } & \multicolumn{2}{|c|}{ Non-Cancer Patients } & \multirow[b]{2}{*}{$p$-Value ${ }^{a}$} \\
\hline & Mean (SD) & Range & Mean (SD) & Range & Mean (SD) & Range & \\
\hline Number of medication (permanent therapy) & $3.80(2.48)$ & $0-12$ & $3.33(2.13)$ & $0-7$ & $4.00(2.61)$ & $0-12$ & 0.305 \\
\hline Number of medication (on demand medication) & $2.44(2.02)$ & $0-12$ & $2.24(1.58)$ & $0-7$ & $2.52(2.19)$ & $0-12$ & 0.595 \\
\hline \multirow[t]{2}{*}{ Medical technology } & $n$ & $\%$ & $n$ & $\%$ & $n$ & $\%$ & $p$-Value ${ }^{b}$ \\
\hline & 75 & 100 & 21 & 100 & 54 & 100 & \\
\hline Any feeding tube & 43 & 57.3 & 1 & 4.8 & 42 & 77.8 & $<0.001 *$ \\
\hline Nasogastric tube & 15 & 20.0 & 1 & 4.8 & 14 & 25.9 & \\
\hline Gastro-or jejunost. tube & 29 & 38.7 & 0 & 0.0 & 29 & 53.7 & \\
\hline Central venous catheter & 15 & 20.0 & 11 & 52.4 & 4 & 7.4 & $<0.001 *$ \\
\hline Tracheostomy & 7 & 9.3 & 0 & 0.0 & 7 & 13.0 & 0.180 \\
\hline Any ventilation & 11 & 14.7 & 0 & 0.0 & 11 & 20.4 & 0.028 \\
\hline Invasive ventilation & 6 & 8.0 & 0 & 0.0 & 6 & 11.1 & \\
\hline Noninvasive ventilation & 5 & 6.7 & 0 & 0.0 & 5 & 9.3 & \\
\hline Oxygen & 25 & 33.3 & 1 & 4.8 & 24 & 44.4 & $0.003 *$ \\
\hline VP/VA shunt & 3 & 4.0 & 2 & 9.5 & 1 & 1.9 & 0.188 \\
\hline Other therapy than medication & 51 & 68.0 & 9 & 42.9 & 42 & 77.8 & $0.008 *$ \\
\hline Physiotherapy & 49 & 65.3 & 8 & 38.1 & 41 & 75.9 & \\
\hline Occupational therapy & 18 & 24.0 & 2 & 9.5 & 16 & 29.6 & \\
\hline Speech therapy & 10 & 13.3 & 0 & 0.0 & 10 & 18.5 & \\
\hline Music therapy & 5 & 6.7 & 0 & 0.0 & 5 & 9.3 & \\
\hline Homeopathy & 5 & 6.7 & 1 & 4.8 & 4 & 7.4 & \\
\hline Art therapy & 1 & 1.3 & 0 & 0.0 & 1 & 1.9 & \\
\hline Acupuncture & 0 & 0.0 & & & & & \\
\hline
\end{tabular}

${ }^{\mathrm{a}} t$-Test; ${ }^{\mathrm{b}}$ Fisher's exact test; ${ }^{*}$ result is significant after Bonferroni-Holm correction; SD, standard deviation; $\mathrm{VP} / \mathrm{VA}$, ventriculoperitoneal/ventriculoatrial.

Patients who were referred to SPPHC services received an average of close to four medications as permanent therapy and two medications as on-demand medication. Patients had a range of 0-12 medications for both categories (see Table 5).

The most common drugs used as permanent therapy were antacids ( $40 \%$ of all patients), followed by anticonvulsants $(35.7 \%)$, and laxatives (32.9\%). Non-opioids were the most common on-demand medications (38.6\%), followed by sedatives and anticonvulsants (nearly $35 \%$ ). Antiemetics were used significantly more often in the cancer group. For further information about medication therapy, see Table 6.

A total of $37.5 \%$ patients ( 27 of 72 ) received strong opioids, either as on-demand medication or as permanent therapy. The primary indications for strong opioids were pain (15 of 27) and dyspnea (10 of 27). Of all 46 patients with pain, twenty patients received strong opioids, fifteen of whom used them as permanent therapy. Seventy-four percent of patients suffering from pain received some type of analgesic as permanent therapy or as on-demand medication. 
Table 6. Medication of cancer and non-cancer patients.

\begin{tabular}{|c|c|c|c|c|c|c|c|}
\hline & \multicolumn{2}{|c|}{ All Patients } & \multicolumn{2}{|c|}{ Cancer Patients } & \multicolumn{2}{|c|}{ Non-Cancer Patients } & \multirow[b]{2}{*}{$p$-Value } \\
\hline & $n$ & $\%$ & $n$ & $\%$ & $n$ & $\%$ & \\
\hline Permanent medication & 70 & 100 & 21 & 100 & 49 & 100 & \\
\hline Antacids & 28 & 40 & 9 & 42.9 & 19 & 38.8 & 0.794 \\
\hline Anticonvulsants & 25 & 35.7 & 4 & 19.0 & 21 & 42.9 & 0.064 \\
\hline Laxatives & 23 & 32.9 & 6 & 28.6 & 17 & 34.7 & 0.783 \\
\hline Immunotherapeutic & 18 & 25.7 & 5 & 23.8 & 13 & 26.2 & 1.000 \\
\hline Vitamin & 17 & 24.3 & 1 & 4.8 & 16 & 32.7 & 0.014 \\
\hline Strong Opioid & 15 & 21.4 & 8 & 38.1 & 7 & 14.3 & 0.053 \\
\hline Antibiotics & 15 & 21.4 & 6 & 28.6 & 9 & 18.4 & 0.356 \\
\hline Broncholytics & 12 & 17.1 & 1 & 4.8 & 11 & 22.4 & 0.092 \\
\hline Non-Opioid & 11 & 15.7 & 5 & 23.8 & 6 & 12.2 & 0.286 \\
\hline Muscle Relaxants & 11 & 15.7 & 0 & 0.0 & 11 & 22.4 & 0.027 \\
\hline Antiemetics & 7 & 10.0 & 6 & 28.6 & 1 & 2.0 & $0.002 *$ \\
\hline Diuretics & 7 & 10.0 & 0 & 0.0 & 7 & 14.3 & 0.094 \\
\hline Sedatives & 4 & 5.7 & 1 & 4.8 & 3 & 6.1 & 1.000 \\
\hline Mild Opioids & 3 & 4.3 & 1 & 4.8 & 2 & 4.1 & 1.000 \\
\hline Antidepressives & 1 & 1.4 & 1 & 4.8 & 0 & 0.0 & 0.300 \\
\hline On demand medication & 70 & 100 & 21 & 100 & 49 & 100 & \\
\hline Non-Opioid & 27 & 38.6 & 7 & 33.3 & 20 & 40.8 & 0.603 \\
\hline Sedatives & 24 & 34.3 & 5 & 23.8 & 19 & 38.8 & 0.280 \\
\hline Anticonvulsants & 24 & 33.8 & 4 & 19.0 & 20 & 40.0 & 0.106 \\
\hline Strong Opioid & 22 & 31.0 & 11 & 52.4 & 11 & 22.0 & 0.023 \\
\hline Laxatives & 16 & 22.9 & 4 & 19.0 & 12 & 24.5 & 0.761 \\
\hline Antiemetics & 15 & 21.4 & 10 & 47.6 & 5 & 10.2 & 0.001 * \\
\hline Mild Opioid & 4 & 5.7 & 1 & 4.8 & 3 & 6.1 & 1.000 \\
\hline
\end{tabular}

\section{Discussion}

The aim of this study was to prospectively describe patients referred to SPPHC teams in Germany. Furthermore, this study aimed to identify differences between non-cancer and cancer patients.

\subsection{The "Typical" Pediatric Palliative Patient}

Characteristics of the pediatric palliative patients in this study are heterogeneous and correspond to those identified in former studies $[5,7,8]$. A one-center study from Germany describes similar characteristics regarding the frequency of non-cancer conditions, age range, symptoms, and medications [5]. In a study by Feudtner and colleagues, which was conducted using a cohort drawn from Canada and the United States of America, similar results were reported [7]. Similarities can especially be found regarding the fitting of feeding tubes, central venous catheters, invasive and non-invasive ventilators, and tracheostomy tubes [7]. The most frequent care goals in the current study have been counseling (93.2\%) and symptom management (89.2\%). Relating burdensome symptoms and the treatment children received at referral indicates that symptom management in primary and secondary care might have not been sufficient (e.g., $25 \%$ of the patients with pain were not treated with analgesics). This is comparable with the results of Feudtner et al. [7], who identified symptom management, communication, and decision-making support as main care goals.

\subsection{Cancer versus Non-Cancer Patients in Pediatric Palliative Care}

Significant differences were identified between cancer and non-cancer patients. Non-cancer patients showed significantly higher rates of swallowing difficulties, spasticity and seizures. While cancer patients displayed a significantly higher rate of being treated with antiemetics and being fitted with a central venous catheter, non-cancer patients were especially fitted with a feeding tube and were treated with non-medication therapies and oxygen. It was only non-cancer patients who were attached to a ventilator or a tracheostomy tube. 
The care goals developed by the SPPHC teams did not differ between the groups. Significant differences did exist, however, within the subgroups of the care categories counsel and empowerment. In the cancer group, the patients themselves required significantly more counseling and empowerment, while in the non-cancer group, the nursing services needed significantly more counseling. This discrepancy is likely due to the high rate of cognitive impairment within the non-cancer group.

In general, the existing care situation for non-cancer patients seems to be more complex upon admission by an SPPHC team and in $14 \%$ of the families more than one child is affected by a life-limiting condition. The patients more often received life-prolonging measures, such as being attached to a ventilator or a feeding tube. Other studies have also shown that non-cancer pediatric patients remain in palliative care longer than cancer patients [8]. Patients with earlier mortality within palliative care more often belong to the cancer group [7]. Children with complex, life-limiting conditions who are referred to a palliative care service, as well as their families, commonly verbalize goals related to health maintenance and independence [9]. These results indicate that care goals in pediatric palliative care are focused not only on end-of-life care but also on life-prolonging measures, such as feeding patients with a feeding tube. However, since the current study did not investigate characteristics at several time points, but rather collected the data only at the time of admission into palliative care, no conclusion can be drawn regarding the course and length of palliative care measures or related mortality.

Both patient groups displayed high demands for the management of symptoms; however, the type and number of symptoms differed. While communication impairments required treatment in $45 \%$ of patients in the cancer group, this was the case for only $19 \%$ of patients in the non-cancer group. Swallowing difficulties required treatment in all cases in the cancer group, while this symptom required treatment in only $64 \%$ of patients in the non-cancer group. Thus, depending on the diagnosis and the current treatment situation, the urgency for treating symptoms may differ.

With regard to care goals and the expected remaining survival time, different measures should be considered. A child suffering from a neuromuscular or neurodegenerative disease who also has swallowing difficulties does not necessarily require any interventions if he or she has already been fitted with a gastro- or jejunostomy tube. A similar child already fitted with a nasogastric tube may need to be fed with a gastro- or jejunostomy tube. A child suffering from an oncologic illness, in which survival time is estimated to be short, the care could include measures such as oral care, temporary provision of nutrients via a nasogastric tube, or parenteral supply of liquids.

\subsection{The Pediatric Patient Compared with Adult Patients in Palliative Care}

Recent studies have shown that pediatric patients differ significantly from adult patients in terms of the spectrum of diagnoses, the number of various symptoms, and the therapeutic measures taken [5].

While adult non-cancer patients account for only $8-23 \%$ of the cases $[4,10,11]$, the proportion of non-oncologic cases of children varies from 70 to $80 \%[5,7,8]$. The most common diagnoses of the non-oncologic group in adults include illnesses affecting the nervous system, heart (e.g., heart failure) and lungs (e.g., chronic obstructive pulmonary disease) [5,11]. Symptoms that appear in most adult cases include tiredness, fatigue, pain and the loss of appetite [5]. This range of symptoms appears to be comparable with that of the oncologic pediatric group in this study and previous studies with pediatric oncology patients [12,13]. The most common symptoms found in the current study, namely, communication impairment, swallowing difficulties, cognitive impairment, seizures, and sleeping difficulties, are of neurological origin.

\subsection{Limitations}

The study has several limitations. First, given the relatively small sample size at each of the nine sites, the data were not analyzed by site, although each site may have had differences in patient populations and consultative practices. However, the sample size is rather typical for studies conducted in pediatric palliative care. Second, symptoms were assessed only by a non-validated proxy-rating 
provided by care takers. It was not assessed with a validated measure provided by self-reports or parent proxy-reports. Third, this was a cross-sectional study and information on the patients' course of disease, treatment process, and outcome were not assessed.

\section{Conclusions}

Patients who are referred to SPPHC teams in Germany are a diverse cohort, often with complex conditions. This complexity is characterized by a large range of differing diagnoses, heterogeneous, and mostly neurologically originating symptoms, and care goals that are focused on prolonging life. To address these goals, teams must be comprised of multiple professionals with different areas of expertise, especially neuropediatrics. The small number of pediatric cases limits the possibilities for conducting controlled studies and, therefore, developing evidence-based treatment guidelines. To overcome these difficulties and ensure high quality palliative care for children, each therapeutic measure must be conducted in close collaboration between the relevant pediatric departments.

Author Contributions: S.N.-B., B.Z., and J.W. were responsible for the conceptualization and methodology of the study. S.N.-B. was responsible for formal analysis, investigation and writing the original draft. B.Z. and J.W. were responsible for writing-review and editing of the manuscript. All authors have seen and approved the final version of the manuscript.

Funding: This research received no external funding.

Acknowledgments: The authors gratefully thank all of the PPC-teams that participated in the research project. This work was initiated during a research workshop on palliative care funded by the Robert-Bosch-Foundation, Germany.

Conflicts of Interest: The authors declare no conflict of interest.

\section{References}

1. Beck, C.H. German Social Law Order Book V-Public Health Sector; Deutscher Taschenbuchverlag: Munich, Germany, 2010; Volume 16, §37b.

2. Groh, G.; Vyhnalek, B.; Feddersen, B.; Führer, M.; Borasio, G.D. Effectiveness of a specialized outpatient palliative care service as experienced by patients and caregivers. J. Palliat. Med. 2013, 16, 848-856. [CrossRef] [PubMed]

3. Schmidt-Wolf, G.; Elsner, F.; Lindena, G.; Hilgers, R.-D.; Heussen, N.; Rolke, R.; Ostgathe, C.; Radbruch, L. Evaluation of 12 pilot projects to improve outpatient palliative care. Dtsch. Med. Wochenschr. 2013, 138, 2585-2591. [PubMed]

4. Heckel, M.; Stiel, S.; Frauendorf, T.; Hanke, R.; Ostgathe, C. Comparison of patients and their care in urban and rural specialised palliative home care-A single service analysis. Gesundheitswesen 2016, 78, 431-437. [PubMed]

5. Groh, G.; Feddersen, B.; Führer, M.; Borasio, G.D. Specialized home palliative care for adults and children: Differences and similarities. J. Palliat. Med. 2014, 17, 803-810. [CrossRef] [PubMed]

6. Lange, M.; Kamtsiuris, P.; Lange, C.; Rosario, A.S.; Stolzenberg, H.; Lampert, T. Sociodemographic characteristics in the german health interview and examination survey for children and adolescents (KIGGS)-Operationalisation and public health significance, taking as an example the assessment of general state of health. Bundesgesundheitsblatt Gesundheitsforschung Gesundheitsschutz 2007, 50, 578-589. [CrossRef] [PubMed]

7. $\quad$ Feudtner, C.; Kang, T.I.; Hexem, K.R.; Friedrichsdorf, S.J.; Osenga, K.; Siden, H.; Friebert, S.E.; Hays, R.M.; Dussel, V.; Wolfe, J. Pediatric palliative care patients: A prospective multicenter cohort study. Pediatrics 2011, 127, 1094-1101. [CrossRef] [PubMed]

8. Siden, H.; Chavoshi, N.; Harvey, B.; Parker, A.; Miller, T. Characteristics of a pediatric hospice palliative care program over 15 years. Pediatrics 2014, 134, e765-e772. [CrossRef] [PubMed]

9. Tamburro, R.F.; Shaffer, M.L.; Hahnlen, N.C.; Felker, P.; Ceneviva, G.D. Care goals and decisions for children referred to a pediatric palliative care program. J. Palliat. Med. 2011, 14, 607-613. [CrossRef] [PubMed]

10. Stiel, S.; Matthies, D.M.; Seuss, D.; Walsh, D.; Lindena, G.; Ostgathe, C. Symptoms and problem clusters in cancer and non-cancer patients in specialized palliative care-Is there a difference? J. Pain Symptom Manag. 2014, 48, 26-35. [CrossRef] [PubMed] 
11. Hess, S.; Stiel, S.; Hofmann, S.; Klein, C.; Lindena, G.; Ostgathe, C. Trends in specialized palliative care for non-cancer patients in germany-Data from the national hospice and palliative care evaluation (hope). Eur. J. Intern. Med. 2014, 25, 187-192. [CrossRef] [PubMed]

12. Friedrichsdorf, S.J.; Postier, A.; Dreyfus, J.; Osenga, K.; Sencer, S.; Wolfe, J. Improved quality of life at end of life related to home-based palliative care in children with cancer. J. Palliat. Med. 2015, 18, 143-150. [CrossRef] [PubMed]

13. Schmidt, P.; Otto, M.; Hechler, T.; Metzing, S.; Wolfe, J.; Zernikow, B. Did increased availability of paediatric palliative care lead to improved palliative care outcomes in children with cancer? J. Palliat. Med. 2013, 16, 1034-1039. [CrossRef] [PubMed]

(C) 2018 by the authors. Licensee MDPI, Basel, Switzerland. This article is an open access article distributed under the terms and conditions of the Creative Commons Attribution (CC BY) license (http:/ / creativecommons.org/licenses/by/4.0/). 